\title{
O uso do princípio da reserva do possível e a política de saúde
}

\author{
The possible reserve principle use and the health policy
}

\section{Alexsandra Santana Nunes* \\ Silvia Alapanian ${ }^{* *}$}

\begin{abstract}
Resumo:
O presente artigo propõe introduzir o leitor nas discussões referentes ao uso do princípio da Reserva do Possível nos litígios relacionados à garantia dos direitos sociais conquistados a partir da Constituição Federal de 1988. Tal princípio se caracteriza pela utilização, por parte dos agentes do Poder Judiciário, de argumentos de natureza preponderantemente econômica em casos que se referem às questões relacionadas com a efetivação de políticas sociais. No Brasil o uso desse princípio vem alcançando cada vez maior legitimidade a partir de seu uso para justificar a negação do acesso aos serviços de saúde tais como medicamentos e procedimentos de alto custo sem cobertura do Sistema Único de Saúde. Discutimos os riscos da utilização desse princípio diante da busca pela consolidação dos direitos sociais como direitos fundamentais do ser humano.
\end{abstract}

Palavras-chave: Direito Público; Direitos Sociais; Reserva do Possível; Políticas Sociais; Política de Saúde.

\begin{abstract}
:
The current article proposes to introduce the reader to the referent discussions use of the Possible Reserve principle in the dispute related to the social life guarantee conquered from the Federal Constitution of 1988. Such a principle is characterized by the use of the Judiciary Power agents, of arguments of especially economical nature in the cases referring to questions related to the effectiveness of social policies. In Brazil the use of this principle has gained more and more legitimacy from its use to justify the access denial of health services such as high cost drugs and procedures with the Health Sole System coverage. We discuss the use risks of this principle before the social rights consolidation search as fundamental rights of the human being.
\end{abstract}

Key words: Public Righ; Social Rights; Possible Reserve; Social Policies; Health Policy.

\footnotetext{
* Assistente Social, pós-graduada em Gestão de Políticas Sociais pela Faculdade de Ciências Contábeis e Econômicas de Apucarana - FECEA/PR. Assistente Social do Instituto de Câncer de Londrina. (e-mail: alesantananunes@yahoo.com.br)

** Assistente Social, doutora em Serviço Social e Política Social pela Pontifícia Universidade Católica de São Paulo, Professora do Departamento de Serviço Social da Universidade Estadual de Londrina. - UEL/PR (email: silviaal@uel.br)
} 


\section{Introdução}

A Constituição Federal de 1988 assegura a todos os cidadãos brasileiros o direito à saúde de forma integral e universal. Entretanto, o instrumento de operacionalização desse direito, o Sistema Único de Saúde - SUS, em muitos momentos não consegue arcar com os custos de procedimentos, medicações e de alguns tratamentos específicos voltados a doenças graves e crônicas.

Diante deste problema, muitos usuários do SUS têm buscado na seara judicial, em geral via Ministério Público, uma alternativa para garantir a efetivação de seus direitos como é o caso das solicitações para a liberação de medicação de alto custo, tratamentos médicos não realizados pelo SUS, entre outros procedimentos.

Entretanto, aqueles que vêm utilizando essa via para garantir seu direito estão se deparando com as pressões advindas do Poder Executivo que alega falta de recursos públicos para efetivação integral do direito à saúde de alguns desses cidadãos. Esses argumentos cada vez mais vêm sendo aceitos e acatados pelos juízes, que reconhecem a falta de recursos como fato e aplicam o princípio da Reserva do Possível no julgamento.

Baseados na premissa de que os desdobramentos do uso desse princípio podem ter significativo impacto na gestão das políticas sociais e na garantia dos direitos sociais conquistados a partir de 1988, buscamos descrever o princípio da Reserva do Possível e o contexto em que ele vem sendo aplicado entre nós, entendendo que a compreensão de suas bases conceituais é fundamental para todos os profissionais que atuam nas áreas relacionadas às políticas sociais.

\section{A estruturação da política de saúde após a Constituição Federal de 1988}

Dentre as profundas mudanças ocorridas na sociedade brasileira a partir de 1988 com o final da ditadura militar e a instituição de uma nova Constituição Federal, a estruturação do SUS, através da Lei Orgânica da Saúde - LOS (Lei Federal 8.080 e 8.142 de 1990) tem significativa importância na organização de um novo modelo de gestão de serviços sociais, mais afinado com as exigências sociais do País.

A Constituição Federal de 1988 propôs a construção de um tripé da Seguridade Social no Brasil organizado através da articulação entre as políticas de saúde, previdência 
social e assistência social. Do ponto de vista da gestão esta deslocou-se da esfera federal para a esfera municipal, introduzindo a participação da sociedade civil organizada e afirmando o direito à saúde, e demais direitos sociais, como direitos fundamentais.

De acordo com Bravo (2006), no que diz respeito à saúde, o texto Constitucional representa a vitória das proposições do movimento da reforma sanitária ${ }^{1}$ que, através da Plenária Nacional de Saúde ${ }^{2}$, via sua capacidade técnica, articulou a mobilização da sociedade e pressionou os constituintes em prol da inclusão na Constituição Federal de artigos que representaram a conquista da saúde como um direito social para toda a sociedade brasileira.

Até então, havia garantia de acesso à saúde somente aos trabalhadores com vínculo empregatício, ou seja, com registro em Carteira de Trabalho e Previdência Social (CTPS), e, portanto com acesso aos serviços do INAMPS, os trabalhadores informais e o restante da população ficavam excluídos desse acesso, submetidos à assistência de caráter filantrópico.

A Carta Magna dedicou cinco artigos à saúde (Arts. 196-200) e, nestes encontramos a proposta da integração dos serviços de forma regionalizada e hierarquizada, constituindo-se num Sistema Único em todo o país. Desta forma, o texto constitucional, construído após vários acordos políticos e sob intensa pressão popular, pretendeu atender grande parte das reivindicações do movimento sanitário.

Do ponto de vista prático, após a aprovação da legislação infra-constitucional, o SUS foi sendo implantado gradativamente, avançando passo a passo em sua construção. Essa organização exigiu a elaboração de novas leis e regulamentação complementar.

A legislação complementar que orientou a regulamentação do Sistema Nacional de Saúde brasileiro foi permeada por confrontos e negociações intensas devido às posições

\footnotetext{
${ }^{1}$ Por volta de 1970 ocorreu uma intensa mobilização política e social que estimulou o campo da saúde, com uma crítica contundente e questionadora de todos os fundamentos básicos dos sistemas de serviços de saúde, sobretudo de assistência médica. É nesse contexto, nacional e global de crise do Estado e de póswelfare, que o movimento sanitário representado pelos profissionais da saúde e suas entidades começam a lutar para defender melhoria da situação da saúde e fortalecimento do poder público.

${ }^{2}$ Segundo Bravo (2006), o processo de democratização dos serviços de saúde e da polarização da discussão da saúde deveu-se também a um bloco denominado Plenária Nacional da Saúde que defendia os ideais da reforma sanitária, que podem ser resumidos como: "a democratização do acesso, a universalidade das ações e a descentralização com controle social". À época, uma emenda popular assinada por cinquenta mil eleitores e cento e sessenta e sete entidades dava a indicação do nível de mobilização obtido.
} 
antagônicas dos grupos de interesses ligados ao setor. Esse conflito provocou um atraso no processo em curso no interior do aparato estatal.

Além disso, já na segunda metade da década de 1990, em meio ao processo de implementação do SUS, os agentes envolvidos em sua operacionalização, bem como os ativistas que atuavam na luta pela garantia desse direito social começaram a apresentar algumas dúvidas e incertezas com relação à concepção proposta pelo projeto da reforma sanitária, tendo em vista as medidas reformadoras econômicas em curso, a minimização do Estado e a redução das manifestações populares na cena pública.

Outro elemento complicador desse processo foi a burocratização presente na gestão do SUS, que, segundo Bravo (2006, p. 99) "[...] afasta a população da cena política, despolitizando o processo". Dessa forma, a população que esteve presente ativamente durante o período decisório foi se afastando, e com isso reduziram-se os níveis de pressão sobre as ações cotidianas dos gestores o que, muitas vezes, compromete o funcionamento do Sistema de acordo com os princípios que o embasaram, ou seja, o princípio da saúde como direito de cidadania, universal e cuja garantia é uma responsabilidade do Estado. Esse complexo cenário caracteriza o contexto no qual as leis complementares da saúde embrionariamente surgiram.

Mesmo assim, diante de tais limitações, a Constituição Federal de 1988 mantêm-se como a base para todas as outras legislações. É dela que emanam as demais leis, inclusive a LOS. Nela estão contidos os princípios para a promoção, proteção e recuperação da saúde, a organização e o funcionamento dos serviços correspondentes. A Lei 8.080/90, em seu art. 4ํㅡ, segue definindo o Sistema Único de Saúde:

Art. 4ㅇ. O conjunto de ações e serviços de saúde, prestados por órgãos e instituições públicas federais, estaduais e municipais, da administração direta e indireta e das fundações mantidas pelo poder público, constitui o Sistema Único de Saúde-SUS. (BRASIL, Ministério da Saúde, 1990).

As reformas ocorridas no setor da saúde não podem ser entendidas somente como reforma administrativa ou processo de descentralização administrativa, mas conforme afirma Sousa (2003): 
[...] a reforma sanitária deve ser compreendida como reforma do modelo assistencial, como nova concepção de saúde, efetivada através de mudanças relacionadas às mais diferentes matrizes: administrativa, cultural, e político-operacional, dentre outras (SOUZA, 2003, p. 69).

Objetivamente, diante do conflito entre o espírito que embase a Lei, as tentativas concretas de colocação em prática de um Sistema de Saúde conforme pensado pelo movimento da reforma sanitária, e a qualidade dos serviços oferecidos à população, temos que o SUS não tem conseguido alcançar a afetividade almejada quando de sua proposição, sobretudo no que diz respeito à abrangência dos serviços. Principalmente se temos como princípio norteador do padrão de qualidade desses serviços, a integralidade da saúde.

Nesse sentido é necessário destacar as manifestações objetivas que buscam, de dentro e de fora do sistema, garantir os princípios que nortearam a organização do SUS, como forma de expandir o conhecimento do direito à saúde e dar mais recursos para o desenvolvimento de um controle, por parte dos usuários, dos serviços prestados e dos limites para sua operacionalização.

Dentre eles está a busca constante pela concretização e garantia do princípio do atendimento integral previsto na Constituição Federal Brasileira de 1988 no seu artigo 198, que é reafirmado e complementado por meio da LOS, e que enfatiza o atendimento integral estabelecendo diretrizes, objetivos, modo de financiamento do SUS, e a organização das ações e serviços de saúde executados diretamente ou mediante participação complementar da iniciativa privada.

Nesta perspectiva é necessário que as pessoas que utilizam os serviços de saúde sejam atendidas de forma ampla envolvendo todas as dimensões humanas. Portanto o Sistema prevê atendimento em equipe multiprofissional, além de um atendimento que não se focalize somente em um problema de saúde, mas que esteja voltado para a garantia da atenção a todos os aspectos da vida do individuo que possam incidir em seu estado de saúde, superando a fragmentação dos serviços.

Por esse motivo, a Lei 8.080/90 -, em idêntica linha, expressa que no campo de atuação do SUS está incluída "[...] a execução de ações de assistência terapêutica integral, inclusive farmacêutica" (artigo 6으, inciso I, alínea $d$ ). A integralidade da assistência é "entendida como o conjunto articulado e contínuo das ações e serviços preventivos e 
curativos, individuais e coletivos, exigidos para cada caso em todos os níveis de complexidade do sistema" (artigo 7으, inciso II, da LOS).

A integralidade de assistência significa que o cidadão tem o direito de ser atendido e assistido sempre que necessitar, em qualquer situação de risco ou agravo, utilizando ou não insumos, medicamentos, equipamentos, entre outros, ou seja, o que define o atendimento deve ser a necessidade das pessoas ou grupo de pessoas.

Para atender tais necessidades são desenvolvidos pelo Ministério da Saúde, programas de atendimento integral à saúde conforme estabelecem as Leis complementares.

Desta forma, cada esfera governamental possui suas responsabilidades especificas junto ao SUS, assim cabe ao Gestor Federal estabelecer normas, promover, por exemplo, a Assistência Farmacêutica, apoiar e implementar consórcios de saúde, promover o uso racional de medicamentos tanto à população, como aos prescritores e aos dispensadores, e otimizar e repassar recursos para a aquisição de medicações a partir do repasse "Fundo a Fundo" para os Estados e Municípios.

Assim, observamos que na década de 1990 a mais importante tarefa no âmbito da saúde foi transformar em realidade os dispositivos formais e legais definidos na Constituição, sintetizados na meta de implantar o SUS. Porém, essa implementação foi trabalhosa devido ao contexto de heterogeneidades regionais e municipais, tanto no que diz respeito ao financiamento, quanto à questão técnica, operacional e organizacional.

Menicucci (2006), chama a atenção aos entraves encontrados na implementação do SUS:

Em que pese os ganhos inegáveis de eficiência e eficácia em relação à cobertura e à qualidade da atenção à saúde, o processo de implementação do SUS tem sido repleto de ambigüidades, avanços e dificuldades, muitos deles já bastante identificados na literatura setorial. Pode-se dizer que a maioria das análises, bem como os esforços para aprimorar o sistema, tem se focado no funcionamento interno do SUS e nas suas condições de operação relacionadas, principalmente, ao financiamento, à capacidade de gestão e a definição dos fluxos assistenciais. Entretanto, razões de natureza exógena ao sistema público, para além das contingências econômicas com suas conseqüências para o financiamento e ampliação do SUS, tem sido, de modo geral, negligenciadas, tanto nas análises com objetivos mais técnicos e práticos, quanto nas pesquisas de caráter acadêmico (MENICUCCI, 2006, p. 59). 
A análise da autora demonstra que a preocupação atual dos gestores está focada no financiamento do SUS a partir de elementos internos ao sistema, menosprezando-se os elementos externos, como as determinantes econômicas gerais, por exemplo. É nesse contexto que se coloca a questão do acesso dos usuários aos medicamentos de alto custo e outros procedimentos de alto custo.

Ao contrário da maioria dos direitos individuais tradicionais, cuja proteção exige apenas que o Estado jamais permita sua violação, os direitos sociais não podem simplesmente ser 'atribuídos' aos cidadãos. Assim, a Constituição prevê que os direitos sociais sejam garantidos por meio de uma ação concreta do Estado que contemple a implementação de políticas públicas. Mas, diante da condição econômica e política do País, fica mais difícil a efetivação desses direitos sociais, por isso, cada vez mais o Poder Judiciário e o Ministério Público vêm intervindo a fim de que esses direitos sejam garantidos.

Neste sentido, conforme o parágrafo primeiro do artigo 5ำ da Constituição Federal a eficácia e aplicabilidade dos direitos sociais constituem matérias mais complexas, especialmente considerando que a concretização de tais direitos muitas vezes exige recursos estatais inexistentes.

\section{O princípio da Reserva do Possível}

Nos primeiros anos que se seguiram à promulgação da Constituição Federal de 1988, a principal tarefa que mobilizou boa parte dos atores sociais foi a luta pela implementação de uma legislação infra-constitucional que garantisse a operacionalização das propostas contidas na Carta Magna. Assim, os limites de implantação dos elementos que compõem a chamada "Ordem Social" na legislação estavam subordinados a construção dessa legislação.

Porém, os limites colocados à operacionalização da política social a partir da segunda metade da década de 1990, já com a maior parte da legislação infraconstitucional construída e em implantação, estimularam novos posicionamentos de alguns desses atores sociais. Diante da constatação de que direitos sociais garantidos em Lei e devidamente regulamentados não vinham sendo concretizados, muitos cidadãos, individual ou coletivamente, passaram a buscar seus direitos nos Tribunais. 
O Ministério Público, por sua vez, exercendo suas atribuições de guardião da legislação, diante do não cumprimento de direitos sociais garantidos em Lei, também passou a interpelar o Poder Executivo através dos Tribunais utilizando de mecanismos como ações civis públicas, entre outros.

Se inicialmente prevalecia um entendimento de que caberia ao Poder Executivo cumprir a legislação, diante das inúmeras intervenções judiciais que tem buscado a garantia e a ampliação de direitos sociais, ocorridas desde a promulgação da Constituição, recentemente temos visto que os Tribunais vêm acatando a alegação da falta de recursos para a implantação das políticas sociais: assim, temos visto ser aplicado nos litígios desta natureza o chamado princípio da Reserva do Possível.

A idéia da Reserva do Possível surge com Peter Häberle ${ }^{3}$ na Alemanha, por volta da década de 70, tendo sido acolhida por primeira vez pela Corte Constitucional Federal daquele país que acatou a alegação da existência de limites econômicos para a efetivação das políticas sociais.

Entenderam os magistrados que caso esses limites não fossem reconhecidos isso poderia comprometer a soberania do país, porque não se pode exigir do Estado o atendimento de um interesse, ou a execução de um direito social em benefício de um individuo sem que se considere os limites financeiros e o principio de isonomia dos cidadãos.

Ocorre que o princípio da isonomia impõe um tratamento idêntico por parte do Estado, em favor de todos os cidadãos que se encontrem em mesma situação de necessidade, não podendo limitar a assistência social aos valores previstos na lei orçamentária anual, sob pena de tratamento desigual. (APPIO, 2005, p.174).

Desta forma, pode-se delimitar o que a população pode esperar da ação governamental.

[...] a construção dogmática da reserva do possível (Vorbehalt des Möglichen) para traduzir a ideia de que os direitos sociais só existem quando e enquanto existir dinheiro nos cofres públicos. Um direito social sob "reserva dos cofres cheios" equivale na prática, a nenhuma vinculação jurídica razoável e possível do Estado em sede de direitos sociais se reconduz à garantia do mínimo social.

\footnotetext{
${ }^{3}$ Häberle, "constitucionalista alemão, autor de teorias que nasceram na Alemanha e ecoaram nas constituições de toda a Europa. Hoje, suas idéias são doutrina em países como a Argentina e o Brasil". (Maiores informações ver CRISTO, 2010).
} 
Segundo alguns autores, porém, esta garantia do mínimo social resulta já do dever indeclinável dos poderes públicos de garantir a dignidade da pessoa humana e não de qualquer densificação jurídico-constitucional de direitos sociais. (CANOTILHO, 1992, p.477).

O autor vincula a efetivação e aplicação das políticas sociais com a possibilidade financeira do Estado em garanti-las, pois não havendo recursos suficientes para concretizar uma política o Estado não poderá ser obrigado a executá-la.

Assim, para firmar esse posicionamento de contenção da efetivação do direito, principalmente a uma solicitação de negação, Garcia (2008) destaca que essa dogmática defende a impossibilidade da intervenção do Judiciário nas políticas públicas, sendo aceitável isso "[...] somente no controle de legalidade do ato administrativo e não na aplicação do direito".

Entretanto, Garcia (2008) explica que há também os que asseguram a possibilidade do Judiciário intervir nas políticas sociais quando houver violação de um direito fundamental, tendo em vista o exercício da democracia e também quando se deparar com casos extremos de violação das prestações de serviços pelo Estado. Considerando a aplicação do mínimo social, pois quando houver uma política já prevista no plano plurianual e que já tenha previsão orçamentária, mas que ainda não foi efetivada há a necessidade do Poder Judiciário intervir, obrigando o Estado a efetivar a política solicitada.

\begin{abstract}
A reserva do possível tem possibilidade de conviver com o mínimo existencial, na medida em que, apenas depois de atingir os elementos fundamentais para a promoção do bem-estar do homem, poderá o Estado discutir, com respeito aos recursos remanescentes, em que outros projetos deverá investir. [...] 0 judiciário somente deve intervir quando o núcleo de algum direito fundamental social - como, e.g., saúde - estiver em verdadeiro risco, ou quando a administração desvirtuar o uso de seu poder discricionário e passar a abusar dele. (GARCIA, 2008, p.84-85).
\end{abstract}

Frente a essa questão convém destacar que os mínimos sociais devem proporcionar a dignidade da pessoa humana.

[...] estabelecer mínimos sociais é mais que um ato jurídico ou um ato formal, pois exige a constituição de um outro estatuto de responsabilidade pública e social. A assistência social e a proposição dos mínimos sociais não se colocam numa concepção 'minimalista' fundada no limiar da sobrevivência, mas numa concepção de mínimos sociais que a considera "ampla e cidadã" e que se fundamenta num "padrão básico de inclusão". Esta perspectiva supõe as 
seguintes garantias: sobrevivência biológica, condições de poder trabalhar, qualidade de vida, desenvolvimento humano e atendimento às necessidades humanas. (SPOSATI, 1997 apud OLIVEIRA, 2007, p.23).

Baseando-se nessa concepção foi que os legisladores do capítulo da "Ordem Social" consagraram a Seguridade Social na Constituição Federal de 1988, assegurando os direitos de cidadania a todo cidadão brasileiro. Mas, a sua aplicabilidade tem sido limitada.

Esta situação vem instaurando-se há tempos e tomando uma dimensão cada vez maior na contemporaneidade, principalmente com a redução dos gastos sociais e a consequente transferência de responsabilidades para a sociedade civil, que é compelida a manter serviços públicos que são de competência do Estado.

A crise que atinge a seguridade social nas sociedades desenvolvidas tem três dimensões. diminuição do contingente de população ativa em relação à inativa: menores taxas de natalidade e mais longevidade fazem com que encargos com idosos, aposentados, doentes crônicos, etc, se tornem pesados. A terceira dimensão, de natureza política, se expressa na insatisfação da população - ou seja, do eleitorado - com a atuação do Estado de Bem-estar. (VIANNA, 1994, p.20).

Buscando problematizar o uso de tal princípio - o da Reserva do Possível - Appio (2005) explica que o Poder Judiciário pode solicitar por meio de instrumentos jurídicos o acesso a programas sociais aos cidadãos que necessitarem, ou que tiverem a negativa do Estado na efetivação de um direito constitucional, também tendo em vista a proteção da isonomia entre os cidadãos.

Entende que o Poder Judiciário pode interpor uma ação embasado na legislação existente, não tendo obstáculos à utilização das verbas do orçamento. Mesmo tendo aumento das despesas com serviços o Poder Executivo deve enviar emenda à lei orçamentária anual junto à Casa Legislativa.

[...] as prestações de natureza coletiva somente poderão ser concedidas ao individuo quando existir uma política pública já implementada através de um sistema de democracia procedimental. Caso já implementada esta política pública, o direito do cidadão poderá ser protegido pelo Poder Judiciário através de ações individuais - como mandado de segurança, por exemplo - a partir da proteção da isonomia entre os cidadãos. (APPIO, 2005, p.179) 
Existe, portanto, a ampliação de um programa social aos indivíduos que necessitarem, sendo protegidos pelo Poder Judiciário que utilizará os instrumento necessários para garantia da efetivação dos direitos sociais.

A Lei 10.837/04 (Lei Orçamentária Anual da União) também dispõe de mecanismos que possibilitam a ampliação de crédito suplementar em caso de gastos com serviços públicos de importância social cuja falta possa provocar prejuízos a população

[...] Se a obra ou serviço tiverem caráter permanente, a decisão judicial deverá determinar a inclusão, na lei orçamentária do ano subsequente, das verbas necessárias ao atendimento desta despesa. Contudo, para o ano em curso, a despesa terá que ser reputada como um serviço extraordinário e sairá dos cofres do Poder Executivo. Para o atendimento de sentenças judiciais já transitadas em julgado, o Poder Executivo está autorizado a abrir créditos suplementares sem percentual definido, mas que provêm do excesso de arrecadação e anulação de despesas. (APPIO, 2005, p.180)

O autor também explica que se busca cumprir a decisão judicial tendo em vista não causar prejuízo a independência dos poderes e sempre utilizando dos créditos abertos ao Poder Executivo na lei orçamentária anual.

Neste sentido, Sarlet (2007) explica que na questão dos direitos sociais o "custo" é relevante para a efetivação e eficácia da aplicabilidade destes direitos. Assim, defende que o uso do princípio da Reserva do Possível, embora possa limitá-los também possui fatores que contribuem na garantia dos direitos fundamentais.

\footnotetext{
A reserva do possível constitui, em verdade (considerada toda a sua complexidade), espécie de limite jurídico e fático dos direitos fundamentais, mas também poderá atuar, em determinadas circunstâncias, como garantia dos direitos fundamentais, por exemplo, na hipótese de conflitos de direitos, quando se cuidar da inovação - observados os critérios da proporcionalidade e da garantia do mínimo existencial em relação a todos os direitos - da indisponibilidade de recursos com o intuito de salvaguardar o núcleo essencial de outro direito fundamental. (SARLET, 2007, p.307)
}

Assim, conforme Appio (2005) é inegável que as políticas sociais devem corresponder a procedimentos democráticos cuja legitimação também dependerá da participação popular, buscando o desenvolvimento de instâncias que consigam mediar os interesses dos cidadãos assegurando a dignidade humana. Ele defende que as políticas públicas, em especial as políticas sociais, são meios para concretização de direitos sociais 
e devem ser formuladas a partir de princípios democráticos. Porém, o controle judicial, por sua vez, precisa estar ligado com princípios como o da isonomia.

Outro ponto levantado pelos defensores do uso do princípio da Reserva do Possível é a questão do Poder Judiciário não poder tornar-se um agente favorecedor ao dano econômico do Estado. Este argumento se escora legalmente no que corresponde à separação dos poderes que vem sendo incentivada pelo princípio da Reserva do Possível.

Entretanto, entre os operadores do Direito e, na lógica do princípio da Reserva do Possível, há uma corrente que defende a possibilidade de intervenção do Judiciário, como anteriormente citado, que reconhece que quando ocorrer uma violação de um direito fundamental, assegurado pela Constituição, cabe sim, ao Poder Judiciário manter a efetivação e garantia desses direitos, seguindo princípios básicos no controle da aplicação da política pública:

Portanto, conforme as palavras de Faria (1994), o Judiciário tem um importante papel na garantia, ampliação e efetivação das políticas públicas, podendo ser um agente favorecedor para sua aplicação.

Nesse ponto, inicialmente, cabe ressaltar um assunto de extrema importância que é a ligação intrínseca entre o direito à saúde e o direito a vida que pode ser desconsiderado em nome da manutenção econômica do Estado.

O direito à vida exige um rol de seguranças sociais como a saúde e a "[...] igualdade de condições sociais, meta a ser alcançada, não só por meio de leis, mas também pela aplicação de políticas ou programas de ação estatal". (COMPARATO, 1996, p.59).

Considerando a necessidade levantada por Comparato (1996) da aplicação de políticas sociais, a solicitação de uma medicação para tratamento de uma doença grave, ou de um exame ou procedimento cirúrgico especial, também complementa a política de saúde porque primeiramente garante o direito à vida.

Segundo Sarlet (apud APPIO, 2005, p. 185) [...] em se cuidando da saúde - da própria vida, integridade da pessoa física e dignidade da pessoa humana, haveremos de reconhecer um direito subjetivo do particular à prestação reclamada em juízo. Assim, a consideração do direito do solicitante é reconhecida, bem como todo o trabalho técnico que foi dispensado no tratamento. 
Embora os direitos sociais tenham alcançado um patamar de legalidade no país como, por exemplo, na política de saúde que estabeleceu em Leis os princípios da universalidade e da integralidade, é necessário observar a recorrência à teoria da "Reserva do Possível" pelos gestores públicos que alegam insuficiência de recursos para manter as ações de saúde, utilizando de argumentos tal como o citado por Canotilho (1992, p. 447) "[...] os direitos sociais só existem quando e enquanto existir dinheiro nos cofres públicos [...]", buscando compreender seus impactos na política em questão.

Assim, busca-se reafirmar que o princípio de que a ordem econômica não pode ser abalada simplesmente para que seja efetivado o direito à saúde a uma pessoa ou a um grupo de pessoas que buscam o acesso a esse direito.

Alguns autores buscam atenuar a questão. Figueiredo, por exemplo, entende que em muitos casos a questão não é de falta de recursos, mas sim do destino que é dado a este, ele refere: "Antes de os finitos recursos do Estado se esgotarem para os direitos fundamentais, precisam estar esgotados em áreas não prioritárias do ponto de vista constitucional e não do detentor do poder" (2007, p. 52).

Acreditamos que assegurar-se no fato de que a operacionalização e ampliação da política de saúde podem ocasionar uma lesão à ordem econômica é desconsiderar que “[...] os direitos sociais requerem do Estado um amplo rol de políticas públicas dirigidas a segmentos específicos da sociedade" (FARIA, 1994, p. 105), mas, que também exige prioridade política e financiamento público, igual ou superior a vários gastos que em muitos momentos não correspondem às necessidades sociais da população.

Na realidade brasileira da atualidade temos visto a utilização desse princípio cada vez com maior freqüência. Um simples medicamento que pode salvar a vida ou mesmo dar maior dignidade a um doente terminal, por exemplo, pode ser negado pelo poder público sem reconhecer o dano causado ao usuário da política de saúde, sendo assegurado esse dano pelo Poder Judiciário com argumentos baseados em tal princípio. ${ }^{4}$

\footnotetext{
${ }^{4}$ Para maiores informações consultar NUNES: 2009. No trabalho intitulado O Principio da "Reserva do Possível" e a garantia do direito a saúde, é apresentado um levantamento de ações judiciais- pedidos de liminares - impetradas pelo Ministério Publico de Londrina -PR para obtenção de medicamentos especiais e de alto custo, sendo observado a utilização, pelo Poder Judiciário, de argumentos relacionados ao princípio da Reserva do Possível, nas sentenças expedidas.
} 


\section{Considerações Finais}

A implantação e organização da política de saúde no País após 1988, através da organização do SUS, tem como premissas os princípios da universalidade de acesso e da integralidade na prestação dos serviços. Assim, temos relacionada essa política ao preceito Constitucional de que os direitos sociais são direito de todos os cidadãos e um dever do Estado a sua garantia.

Como direito fundamental, a saúde, para chegar à sua efetivação, necessita alcançar todas as dimensões humanas de cuidados e uma série de mecanismos estão previstos na legislação infra-constitucional, que garantem esse direito. Exemplos desses mecanismos são a política nacional de medicamentos excepcionais que visa garantir o acesso a medicamentos de alto custo ao tratamento de doenças graves e crônicas que são de difícil acesso a população usuária do SUS.

Nesses casos, principalmente, é que se tem observado os limites de aplicabilidade do direito à saúde em sua integralidade, de acordo com as demandas da população. Aqueles que têm buscado a sua garantia pela via judicial, tem se deparado com o crescimento da aceitação do argumento da falta de recursos para sua efetivação, através do que compõem o chamado princípio da Reserva do Possível.

O Poder Judiciário vem julgando improcedentes os pedidos de concessão de medicamentos e tratamentos excepcionais, além de não se considerar apto para determinar a efetivação da política social, alegando que essa prerrogativa seria exclusiva do Poder Executivo. Assim, desconsidera que em muitos momentos a ação do Poder Judiciário pode representar a garantia de efetivação de políticas essenciais à própria manutenção da vida dos sujeitos.

Nesta perspectiva, a falta de recursos econômicos, caso não reconhecida, poderia causar lesão à ordem pública. Este se constitui como o mais importante argumento utilizado com o fim de se evitar um alegado colapso na gestão dos recursos públicos, o qual nos remeteria à necessária aceitação do uso do princípio da Reserva do Possível que assegura essa prerrogativa.

Este contexto vem se constituindo hoje em um grande desafio a toda a sociedade, e em especial ao sistema de justiça, que compreende o Poder Judiciário e o Ministério Público, entre outros organismos, no direcionamento das políticas sociais, principalmente 
no sentido de implementação dos direitos fundamentais que garantem a dignidade humana.

Entendemos que a ampliação da utilização de argumentos desse tipo, em suma, a ampliação do uso do princípio da Reserva do Possível pode, no limite, significar o fim dos direitos sociais conquistados na Constituição Federal de 1988, tornando-se assim, necessário e urgente o aprofundamento da compreensão do uso desse princípio como um mecanismo de cerceamento dos direitos sociais.

\section{Referências}

APPIO. E. Controle judicial das políticas sociais no Brasil. Curitiba: Juruá, 2005.

BRASIL. [Constituição (1988)]. Constituição da República Federativa do Brasil. 27.ed. São Paulo: Saraiva,1996.

BRASIL. Lei no 8.080 de 19 de setembro de 1990. Dispõe sobre as condições para promoção, proteção e recuperação da saúde, a organização e o funcionamento dos serviços correspondentes e dá outras providências. Brasília, 1990. Disponível em: <http://ministerio.saúde.gov.br >. Acesso em: 13 out. 2008.

BRAVO, M.I.S. Política de Saúde no Brasil. In: MOTA, A. et al. Serviço social e Saúde. São Paulo: OPAS, 2006. p, 88-110.

CANOTILHO, J. J. G. Constituição dirigente e vinculação do legislador. Coimbra: Coimbra, 1982. 2002.

Direito Constitucional e teoria da constituição. 5. ed. Coimbra: Livraria Almedina,

COMPARATO,Fabio Konder. Direito público: estudos e pareceres. São Paulo: Saraiva, 1996.

CONH, A. Saúde no Brasil: políticas e organização de serviços. 2 ed. São Paulo: Cortez: CEDEC,1998.

CRISTO. A. Repúblicas jovens dependem de ativismo judicial. Disponível em: <www.conjur.com.br/2010-fev-13/entrevista-peter-haberle-constitucionalista-alemao>. Acesso em: 28 fev. 2010.

FARIA, J. E. Direitos humanos, direitos sociais e justiça. São Paulo: Malheiros, 1994.

FIGUEIREDO. M. O controle das políticas públicas pelo poder judiciário no Brasil uma visão geral. Interesse Público, Belo Horizonte, ano 9, n.44. jul./ago.2007. 
GARCIA, R. B. O Poder Judiciário e as políticas públicas no Brasil: análise doutrinária evolução casuística. Interesse Público, Belo Horizonte, ano 10. n.51.set./out.2008.

MENICUCCI, T.M.G. Política de saúde no Brasil: entraves para universalização e igualdade da assistência no contexto de um sistema dual. Revista Serviço Social e Sociedade, São Paulo, n. 87, ano 26, p. 58-75, 2006.

OLIVEIRA. I. M. Direitos, cultura de direitos e assistência social. Revista Serviço Social \& Sociedade, São Paulo, n. 89, ano 28, mar. 2007.

NUNES, A. S. O principio da "reserva do possível" e a garantia do direito a saúde. 2009. Monografia (Especialização) - Faculdade de Ciências Contábeis e Econômicas de Apucarana, Apucarana.

SARLET. I. W. A eficácia dos direitos fundamentais. 9.ed. Porto Alegre: Livraria do advogado. 2007.

VIANNA. M. L. T. Werneck. Seguridade social: imprecisão conceitual de uma prática consolidada. In: BRASIL. Ministério da Previdência social. A Previdência Social e revisão constitucional. Brasília, 1994.

VIEIRA, A.C. S. O direito à vida na questão das políticas sociais. Revista Serviço social e Realidade de Franca, Franca-SP, p. 1-28, 2007. 